\title{
KOtBu: A Privileged Reagent for Electron Transfer Reactions?
}

\author{
Joshua P. Barham, ${ }^{\dagger, \dagger, \perp}$ Graeme Coulthard, ${ }^{\dagger, \perp}$ Katie J. Emery, ${ }^{\dagger}$ Eswararao Doni, ${ }^{\dagger}$ Florimond Cumine, ${ }^{\dagger}$ \\ Giuseppe Nocera, ${ }^{\dagger}$ Matthew P. John, ${ }^{\ddagger}$ Leonard E. A. Berlouis, ${ }^{\dagger}$ Thomas McGuire, ${ }^{\S}$ Tell Tuttle, ${ }^{*}{ }^{\dagger}$ \\ and John A. Murphy* ${ }^{\dagger}$
}
${ }^{\dagger}$ WestCHEM, Department of Pure and Applied Chemistry, University of Strathclyde, 295 Cathedral Street, Glasgow G1 1XL, U.K.
${ }^{\ddagger}$ GlaxoSmithKline Medicines Research Centre, Gunnels Wood Road, Stevenage SG1 2NY, U.K.
${ }^{\S}$ AstraZeneca R\&D, The Darwin Building, Milton Road, Milton, Cambridge CB4 0FZ, U.K.

\section{Supporting Information}

ABSTRACT: Many recent studies have used $\mathrm{KO} t \mathrm{Bu}$ in organic reactions that involve single electron transfer; in the literature, the electron transfer is proposed to occur either directly from the metal alkoxide or indirectly, following reaction of the alkoxide with a solvent or additive. These reaction classes include coupling reactions of halobenzenes and arenes, reductive cleavages of dithianes, and $S_{\mathrm{RN}} 1$ reactions. Direct electron transfer would imply that alkali metal alkoxides are willing partners in these electron transfer reactions, but the literature reports provide little or no experimental evidence for this. This paper examines each of these classes of reaction in turn, and contests the roles proposed for $\mathrm{KO} t \mathrm{Bu}$; instead, it provides new mechanistic information that in each case supports the in situ formation of organic electron donors. We go on to show that direct electron transfer from $\mathrm{KO} t \mathrm{Bu}$ can however occur in appropriate cases, where the electron acceptor has a reduction potential near the oxidation potential of $\mathrm{KO} t \mathrm{Bu}$, and the example that we use is $\mathrm{CBr}_{4}$. In this case, computational results support electrochemical data in backing a direct electron transfer reaction.

\section{INTRODUCTION}

Alkali metal tert-butoxides $(\mathrm{KO} t \mathrm{Bu}, \mathrm{NaO} t \mathrm{Bu})$ play key roles in numerous organic transformations, acting as powerful bases. In recent years, they have seen widespread use in transition metalfree coupling reactions of haloarenes $\mathbf{1}$ with arenes to afford biphenyls 2 (here the arene is the solvent) ${ }^{1-9}$ or with styrenes to afford stilbenes. ${ }^{2 e, 3 a, 6 c}$ The mechanism for biaryl formation is shown in Scheme 1A. ${ }^{10}$ Here, KOtBu has a dual role: (i) acting in combination with a wide variety of organic additives to initiate the process by converting aryl halides $\mathbf{1}$ into aryl radicals 3 and (ii) deprotonating radical $\mathbf{4}$ to form the radical anion 5; this radical anion transfers an electron to another molecule of aryl halide 1 (shown in blue), thereby propagating a chain reaction. The role of $\mathrm{KO} t \mathrm{Bu}$ in the activation of the aryl halides 1 is the subject of wide discussion, with some authors proposing electron transfer from the tert-butoxide anion, alone or as part of a complex, to the aryl halide. ${ }^{5 e, 6 e, 7}$ A related but different class of reactions arises from $\mathrm{KO} t \mathrm{Bu}$ in $\mathrm{DMSO}$ as solvent. Peñénory et al. reported ${ }^{11}$ reductive cleavage of dithianes, for example, 6, with $\mathrm{KO} t \mathrm{Bu}$ in DMSO under photoactivated conditions, proposing that the reaction was triggered by direct electron transfer from $\mathrm{KO} t \mathrm{Bu}$ to the dithiane within a charge-transfer complex (Scheme 1B). In 2015 using $\mathrm{KO} t \mathrm{Bu}$ in $\mathrm{DMF}$ as solvent, Taillefer et al. reported ${ }^{12} \mathrm{~S}_{\mathrm{RN}} 1$ coupling reactions between potassium enolates $\mathbf{1 0}$ and aryl radicals 3 , the latter being formed from aryl halides $\mathbf{1}$.

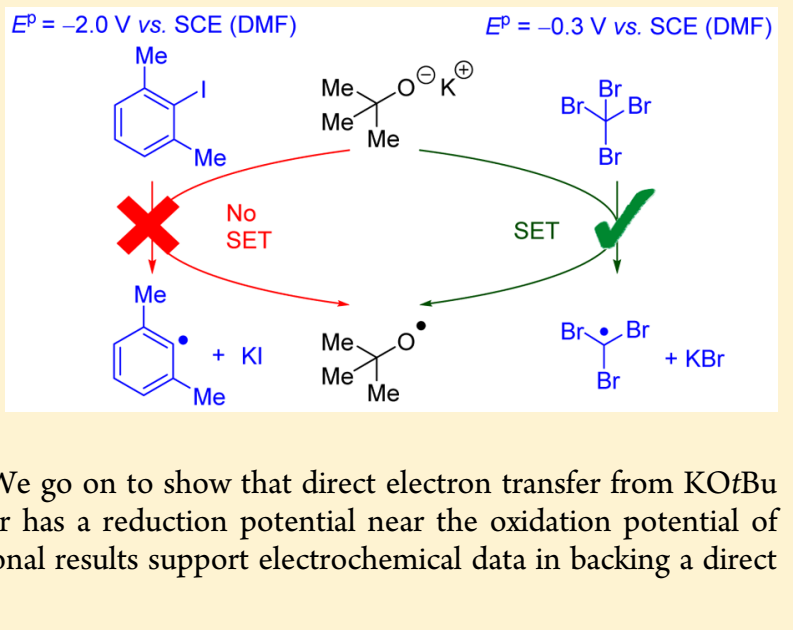

These reactions afforded ketones $\mathbf{1 2}$ as the final products (Scheme 1C). DMF was uniquely useful in accomplishing these reactions. Through computational studies, they proposed that, following deprotonation of DMF to form carbamoyl anion 8, electron transfer occurred to the aryl halide 1, thereby generating an aryl radical $\mathbf{3}$ and carbamoyl radical 9, although no experimental evidence for electron transfer was presented. Whereas $\mathrm{KO}$ tBu worked well, the corresponding sodium and lithium salts were not effective. Thus, it appears that $\mathrm{KO} t \mathrm{Bu}$ is deeply implicated in a wide variety of electron transfer reactions, either directly or indirectly. This paper examines, in turn, the evidence in each of these cases.

\section{TRANSITION METAL-FREE COUPLING REACTIONS}

The coupling reactions of Scheme $1 \mathrm{~A}$ are accomplished in the presence of different classes of organic additives. In two recent papers, ${ }^{5 \mathrm{~b}, \mathrm{f}}$ we made a proposal, backed by experimental evidence, that these reactions generically involve reaction between $\mathrm{KO} t \mathrm{Bu}$ and the organic additive to form an organic electron donor ${ }^{8,13}$ and that this species, rather than a tertbutoxide anion, is responsible for electron transfer to aryl halides.

Received: March 30, 2016 


\section{Scheme 1. KOtBu Implicated in SET Processes}
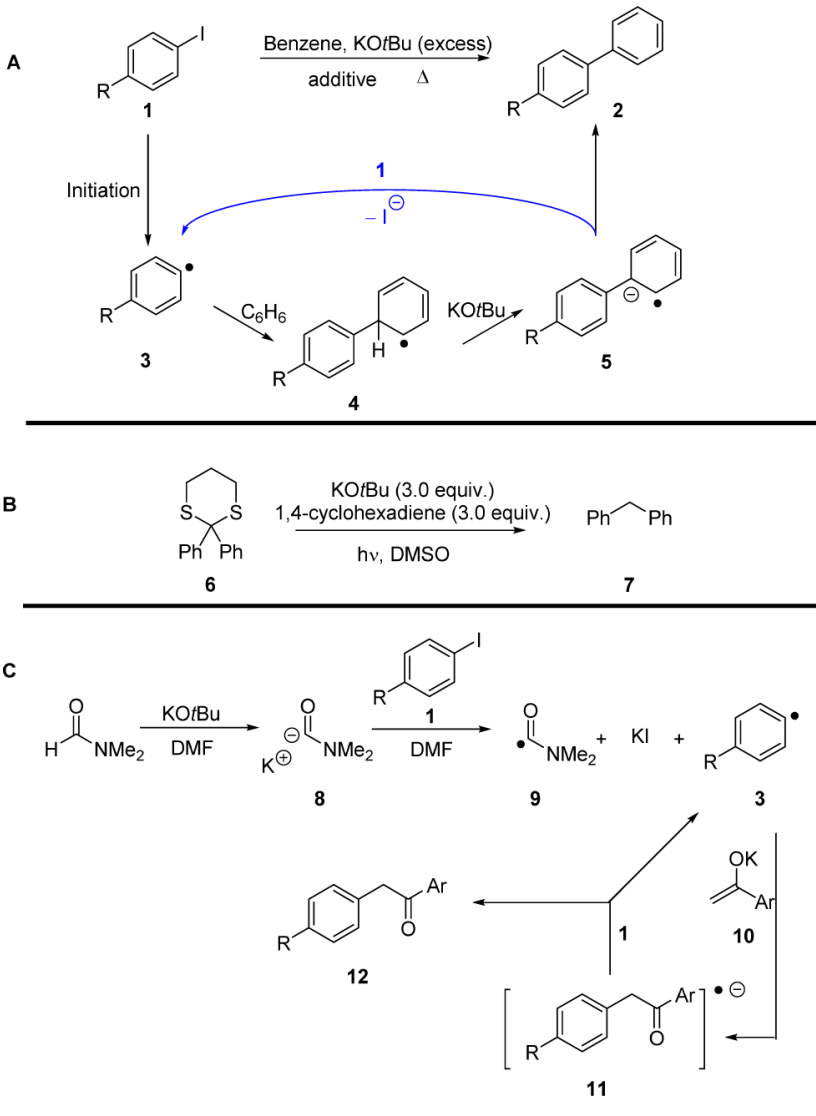

One of the popular organic additives in these reactions is phenanthroline 21 (Scheme 2 ). It was originally proposed ${ }^{1 \mathrm{~b}, \mathrm{c}}$ that the complex 13 might directly donate an electron to an aryl iodide 14 to form complex 15, together with an aryl radical 16 and iodide anion. Our recent paper $^{5 \mathrm{~b}}$ reported that such an electron transfer reaction from $\mathrm{KO} t \mathrm{Bu}-$ phenanthroline complex 13 to iodobenzene was endergonic by about $60 \mathrm{kcal} \mathrm{mol}^{-1}$ in benzene as solvent and hence unlikely to play a role., ${ }^{72}$ Rather, we reacted $\mathrm{KOtBu}$ with phenanthroline $\mathbf{2 1}$ and identified organic electron donor activity. Quenching with iodine as an electron acceptor afforded a dimer $\mathbf{2 0}$ in $38 \%$ yield. $^{5 \mathrm{~b}}$ This implicated 19 as the in situ-formed electron donor to iodobenzene 14. Since that time, papers have emerged from Wilden et al., ${ }^{5 e}$ and from Jutand and co-workers ${ }^{6 e}$ that add to the debate. In addition, Patil has just published a computational paper $^{7}$ that examines a wide range of potential electron donors. ${ }^{14}$

The Jutand and co-workers ${ }^{6 e}$ paper used EPR spectroscopy to identify formation of phenanthroline-type radical anions, when phenanthroline was treated with $\mathrm{KO} t \mathrm{Bu}$ in organic solvents. Their finding was unexpected and led them to propose that tert-butoxide anion $\mathbf{2 4}$ must be donating an electron to phenanthroline $\mathrm{e}^{5 \mathrm{e}}$ to afford the delocalized phenanthroline radical anion 22. Such delocalized radical anions are relatively long-lived and so could be detected by EPR.

Examination of their EPR spectrum resulting from reaction of $\mathrm{KO} t \mathrm{Bu}$ with phenanthroline in DMF as solvent (Figure 2a in that paper $^{6 \mathrm{e}}$ ) shows fine structure, but the spectrum is not a symmetrical spectrum, with the possibility that more than one
Scheme 2. Phenanthroline and KOtBu as Precursors to Electron Donors

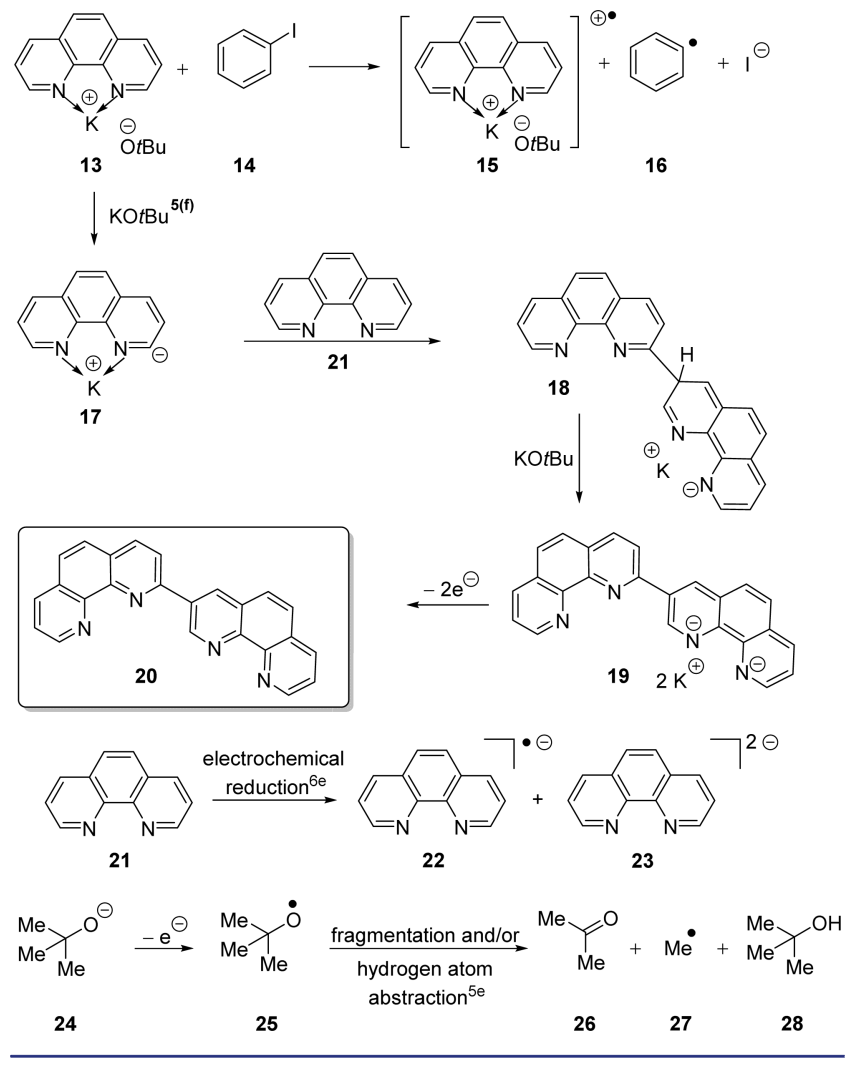

phenanthroline-related radical anion may be present, with superposition of the similar spectra causing the asymmetry.

We repeated the reaction of Jutand and Lei, and from EPR spectra, we confirm that radicals are indeed formed. However, given the fact that we have demonstrated that electron donor 19 is formed from phenanthroline and $\mathrm{KO} t \mathrm{Bu},{ }^{5 b}$ we propose that, in the absence of a better electron acceptor (i.e., unlike the coupling reactions, no aryl halide is present in the EPR experiments), 19 donates an electron to phenanthroline to form two radical anions, that is, the radical anions of phenanthroline $\mathbf{2 1}$ and of 20, and these species together could contribute to the reported EPR spectrum. As will be seen below, the reduction potential of phenanthroline $\mathbf{2 1}$ and the oxidation potential of dianion 19 are compatible with electron transfer between the species. ${ }^{15}$

Jutand and Lei's paper ${ }^{6 e}$ also investigated the electrochemical properties of phenanthroline. From cyclic voltammetry (CV), reduction of phenanthroline gave rise to phenanthroline dianion 23 and phenanthroline radical anion 22. They demonstrated that $\mathbf{2 3}$ is a strong enough electron donor to reduce bromobenzene and that $\mathbf{2 3}$ can also reduce phenanthroline 21 to its radical anion 22. They also showed that radical anion 22 was able to activate $\mathrm{PhBr}$. They observed that the electrochemical reduction of phenanthroline $\mathbf{2 1}$ was inhibited in the presence of $\mathrm{KO} t \mathrm{Bu}$ due to a chemical reaction between $\mathrm{KO} t \mathrm{Bu}$ and phenanthroline. This latter finding is entirely consistent with our picture (Scheme 2, formation and reaction of 17). The difference between our viewpoints is that our evidence points toward dianion 19 as the reactive electron donor, formed from reaction of $\mathrm{KO} t \mathrm{Bu}$ with phenanthroline, and backed by the isolation and characterization of $\mathbf{2 0}$ following electron transfer. ${ }^{5 \mathrm{~b}}$ 
To gain insight, we explored the $\mathrm{CV}$ of $\mathbf{2 0}$ for comparison with phenanthroline 21. Operating under Jutand and Lei's conditions $^{6 e}\left(0.3 \mathrm{MnBu}_{4} \mathrm{NBF}_{4}\right.$ in DMF, $0.5 \mathrm{~V} \mathrm{~s}^{-1}$ scan rate, $\mathrm{Pt}$ wire electrode), our $\mathrm{CV}$ for phenanthroline 21 matched theirs $\left(E^{\mathrm{p}}=-2.05,-2.24 \mathrm{~V}\right.$ vs. SCE $)$; the dimer 20 exhibited three peaks $\left(E^{\mathrm{p}}=-1.70,-1.94,-2.19 \mathrm{~V}\right.$ vs. SCE (see Figure 1).

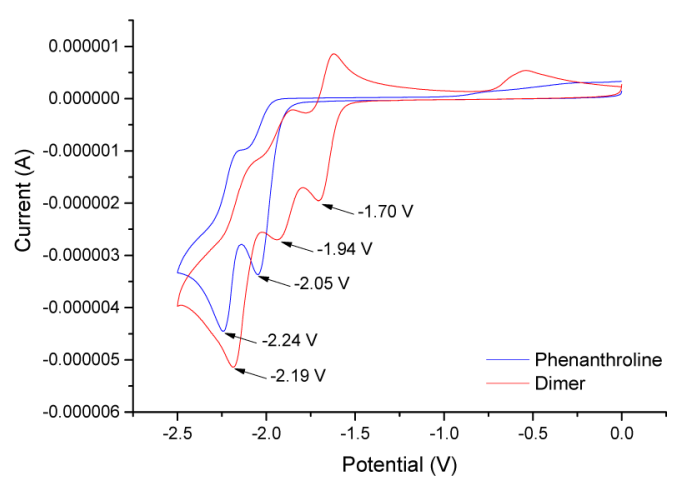

Figure 1. Cyclic voltammograms of phenanthroline $\mathbf{2 1}$ and dimer 20.

Calibration with $\mathrm{Fc} / \mathrm{Fc}^{+}$showed that these reductions of $\mathbf{2 0}$ corresponded, respectively, to $1 \mathrm{e}^{-}, 1 \mathrm{e}^{-}$, and $2 \mathrm{e}^{-}$, with all steps being reversible (see SI for analysis). Considering the first and second potentials for reduction of dimer 20, respectively, associated with the formation of the radical anion (structure not shown here) and dianion 19, both these species are significantly more reducing than all our previous neutral organic electron donors, which easily reduce aryl iodides (ArI, $E^{\mathrm{P}}=$ $-2.0 \mathrm{~V}$ vs. SCE in DMF), and hence are competent electron donors to achieve the previously reported coupling reactions of iodoarenes with arenes. ${ }^{13}$ Importantly, Jutand and Lei record the oxidation potential of tert-butoxide anion from $\mathrm{KO} t \mathrm{Bu}$ at $+0.10 \mathrm{~V}$ vs. SCE in DMF, ${ }^{\text {6e }}$ and they show by cyclic voltammetry that it does not directly reduce aryl halides. This would also make it very unlikely to reduce phenanthroline $\mathbf{2 1}$ or its derived complex 13. In contrast, the close matching of potentials for oxidation of dianion 19 and for reduction of phenanthroline $\mathbf{2 1}$ indicates that reduction of phenanthroline to its radical anion by dianion 19 should be possible, thereby forming two phenanthroline-related radical anions, and providing a rationalization for the EPR spectrum reported in the Jutand and Lei paper. ${ }^{6 e}$

Although their paper proposes electron transfer from tertbutoxide anion to phenanthroline thereby affording a reducing species, in fact no evidence is present to support electron transfer specifically from tert-butoxide anion.

The other paper that gives a different mechanistic picture than ours on the coupling reactions is presented by Wilden et al., ${ }^{5 e}$ who employ $\mathrm{KO} t \mathrm{Bu}$ with phenanthroline 21 to effect couplings but who also observed coupling in the absence of phenanthroline. The authors attributed this latter phenomenon to electron transfer from $\mathrm{KO} t \mathrm{Bu}$ directly to the aryl iodide, when conducted in the absence of phenanthroline; in contrast, when phenanthroline is present, they propose electron transfer from tert-butoxide anion to phenanthroline. Coupling in the presence of $\mathrm{KO} t \mathrm{Bu}$ and in the absence of additives had previously been reported by Bisai et al..$^{3 \mathrm{~g}, 4 \mathrm{e}} \mathrm{We}$ went on to propose that, while organic additives in the presence of $\mathrm{KO} t \mathrm{Bu}$ form organic electron donors that convert aryl iodides to aryl radicals, ${ }^{\mathrm{Bb}, \mathrm{f}}$ a second and more sluggish activation can occur in the background in the absence of additives via benzyne 29
(Scheme 3). (We have repeated the reaction under the Wilden conditions in the absence of phenanthroline and find

Scheme 3. Evidence for Initiation by Benzyne ${ }^{5 b}$

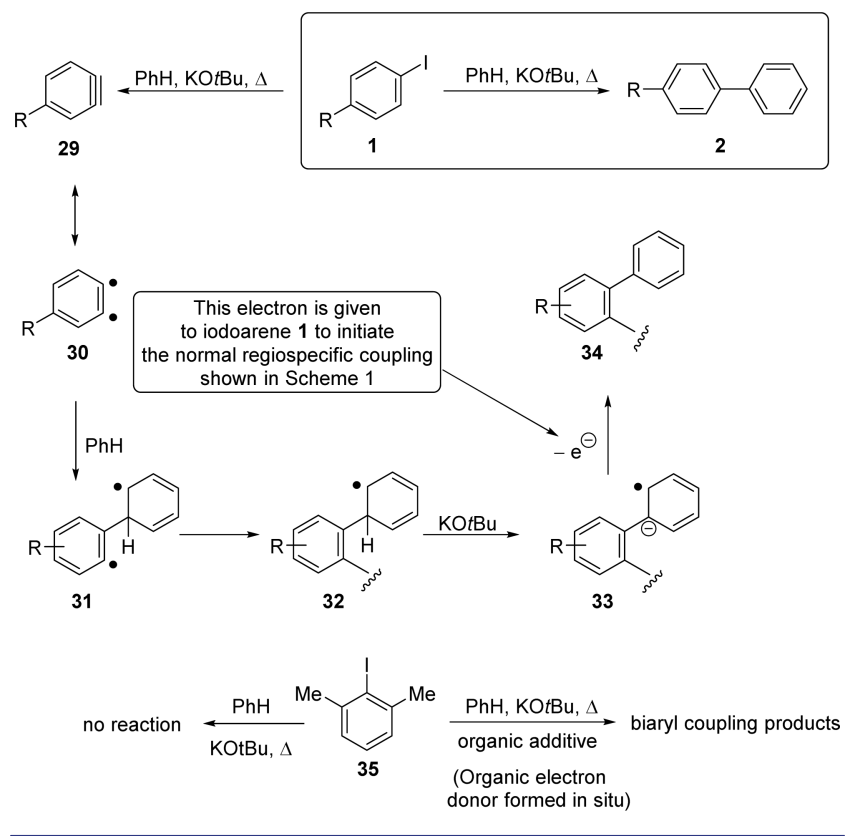

unambiguous evidence for benzyne formation. See SI file. ${ }^{16}$ ) Benzyne can function as a diradical, 30, that initiates the coupling reactions by occasionally adding to the benzene solvent to form distal diradical 31. ${ }^{5 f}$ Some of these radicals react further (e.g., by addition of the reactive aryl radical to a further molecule of benzene) to form arylcyclohexadienyl radical 32, and this suffers deprotonation by $\mathrm{KO} t \mathrm{Bu}$ to afford electron donor 33, which donates an electron to iodoarene 1 to start the much faster cycle shown in Scheme 1A leading to biaryl 2 . When the propagation cycle in Scheme 1A is much faster than the benzyne initiation, the isolated products arise overwhelmingly from the reaction cycle in Scheme 1A and show apparent site-specific arylation at the iodine-bearing carbon of 1. This is in line with observed outcomes from these coupling reactions.

An important piece of evidence to support our benzyne proposal was that reaction of 2,6-dimethyliodobenzene 35 in benzene, in the presence of $\mathrm{KOtBu}$ but in the absence of any organic additive, gave no coupled product. ${ }^{5 f}$ For this substrate, formation of benzyne would not be possible. However, in the presence of a range of organic additives (that give rise to organic electron donors in situ on reaction with $\mathrm{KO} t \mathrm{Bu}$ ), coupling is seen with substrate $\mathbf{3 5}$.

A number of interesting observations from Wilden et al. appear to provide support for their proposals, and so we address these. One of the outcomes that would arise from conversion of tert-butoxide ion 24 to tert-butoxyl radical 25 would be the known fragmentation of this radical to acetone 26 and methyl radical 27 (Scheme 2). ${ }^{17}$

To model this, Wilden added 1,3-dinitrobenzene 36 (Scheme 4) to a dilute THF solution of an equimolar mixture of potassium tert-pentoxide (an analogue of $\mathrm{KO} t \mathrm{Bu}$ ) and phenanthroline 21, and this resulted in an intense purple color. This was regarded as a positive Janovsky test, which reports the presence of an enolizable ketone or aldehyde. ${ }^{18}$ This result was taken as evidence for the presence of a significant amount of 
Scheme 4. Mechanistic Considerations in the Formation of Janovsky Adducts

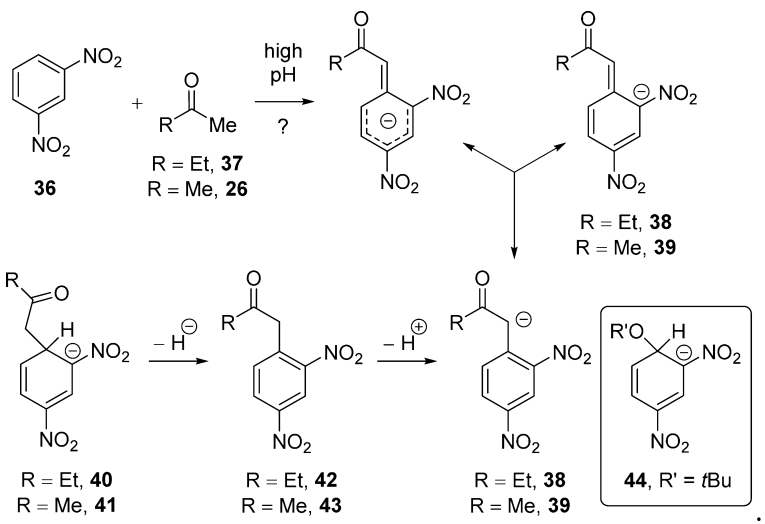

butanone 37, which was proposed to result from the collapse of a tert-pentoxyl radical, itself arising from the transfer of an electron from the tert-pentoxide anion (analogous to what is shown for tert-butoxide anion $\mathbf{2 4}$ in Scheme 2) to phenanthroline.

It was proposed that, under alkaline conditions, the enolate of butanone adds to 1,3-dinitrobenzene 36 to give a colored adduct that was represented as $\mathbf{3 8}$ (Scheme 4). ${ }^{\text {5e }}$ In alkaline conditions (high $\mathrm{pH}$ ), if any ketone were present, the product resulting from the addition of the same enolate of butanone to 1,3-dinitrobenzene would initially be adduct 40 , and this would require oxidation to afford 38 . $^{18}$

We now performed a number of experiments. Experiment a, when $\mathrm{KOtBu}$ ( 1 equiv), acetone ( 1 equiv), and 1,3dinitrobenzene ( 1 equiv) were combined in THF, a purple color and UV-vis absorption at $552 \mathrm{~nm}$ resulted (Figure 2,

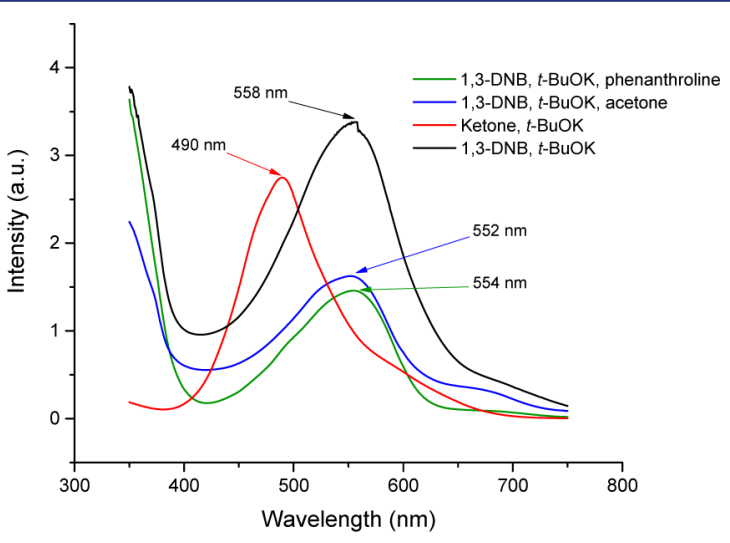

Figure 2. UV-visible spectroscopy of Janovsky tests.

blue trace). The result was always the same, regardless of the order of addition (see SI for full details). Previous NMR studies by Fyfe and Foster ${ }^{18 \mathrm{~d}}$ disclosed the ${ }^{1} \mathrm{H}$ NMR spectrum of adduct 41 when treating 1,3-dinitrobenzene in acetone solution with $\mathrm{NaOMe}$, and current NMR studies mirrored those findings (See Supporting Information), so this is the normal Janovsky test outcome.

Experiment b, when we dissolved phenanthroline ( 1 equiv) and $\mathrm{KO} t \mathrm{Bu}$ ( 1 equiv) in $\mathrm{THF}$ and stirred at room temperature for $2 \mathrm{~h}$ and then 1,3-dinitrobenzene 36 ( 1 equiv) was added, a purple coloration was again observed and an absorption at 554 $\mathrm{nm}$ detected (Figure 2, green trace).
To probe further, we prepared ketone $\mathbf{4 3}$ by an independent route. In experiment $c$, when this ketone ( 1 equiv) was dissolved in $\mathrm{THF}$ and $\mathrm{KO} t \mathrm{Bu}$ ( 1 equiv) was added, a purple color was again seen. However, this color was slightly different than in the previous cases, and the UV-vis spectrum of the solution showed a different absorption, at $490 \mathrm{~nm}$ (red trace), attributable to 39 , rather than the $552-554 \mathrm{~nm}$ previously seen. This clearly demonstrated that the purple coloration mentioned above, resulting from the reaction of $\mathrm{KO} t \mathrm{Bu}$ with phenanthroline mixture in experiment $\mathrm{b}$ was not due to the presence of adduct 39.

Finally, we ran a test in the absence of acetone $\mathbf{2 6}$ and in the absence of phenanthroline 21: in experiment $\mathrm{d}, \mathrm{KO} t \mathrm{Bu}$ ( 1 equiv) was dissolved in THF and 1,3-dinitrobenzene 36 (1 equiv) was added. The result was striking; a purple color was obtained and a UV-vis absorption at $558 \mathrm{~nm}$ (black trace in Figure 2) was detected. This result was indistinguishable from that when a ketone was present in the mixture and indicates that observation of a purple color in the Janovsky test is not sufficient to confirm the presence of a ketone. Having confirmed that the species giving rise to a purple color in experiment $\mathrm{b}$ when $\mathrm{KO} t \mathrm{Bu}$, phenanthroline, and 1,3dinitrobenzene are simply mixed cannot be 39 , we propose 44 as a more likely candidate. Indeed, in the absence of added acetone, instantaneous addition of alkoxides to 1,3-dinitrobenzene 36 was observed by ${ }^{1} \mathrm{H} \mathrm{NMR}$, and this was accompanied by the same purple color (See Supporting Information).

Wilden's paper had also reported that when a mixture of phenanthroline and $\mathrm{KO} t \mathrm{Bu}$ was prepared and observed by $\mathrm{NMR}$, the intensity of the $t \mathrm{Bu}$ signal dramatically decreased almost immediately, indicating that $\mathrm{KO} t \mathrm{Bu}$ was rapidly consumed in a reaction. In our hands, phenanthroline and $\mathrm{KO} t \mathrm{Bu}$ were mixed in THF- $d_{8}$ at room temperature under an inert atmosphere for $2 \mathrm{~h}$, and then the mixture was analyzed directly by ${ }^{1} \mathrm{H}$ NMR (Figure 3 ). Importantly, and in contrast to the reported observations, we saw no collapse of the tertbutoxide signal, and the two reagents were unchanged.

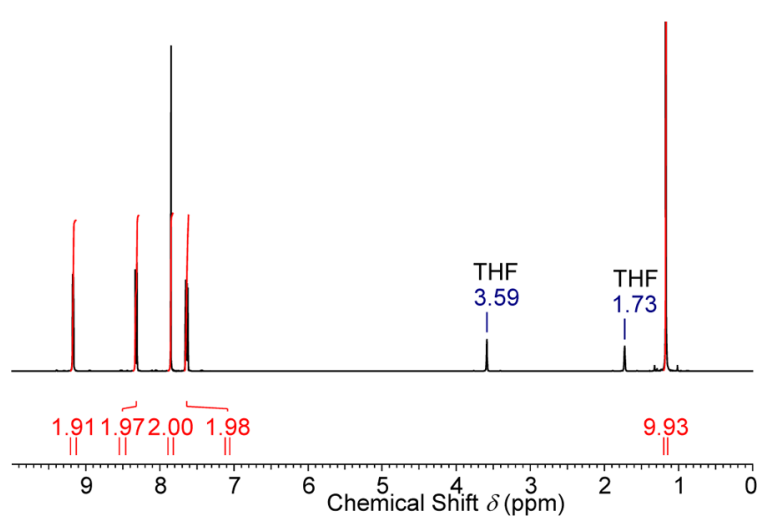

Figure 3. ${ }^{1} \mathrm{H}$ NMR of phenanthroline and $\mathrm{KO} t \mathrm{Bu}(1: 1)$ in THF- $d_{8}$ after $2 \mathrm{~h}$ at room temperature, showing unchanged reagents and no collapse of the tert-butoxide peak at $1.2 \mathrm{ppm}$.

Examination of the spectrum published by Wilden et al. ${ }^{5 \mathrm{e}}$ shows a singlet signal at $7.28 \mathrm{ppm}$ that could be due to residual $\mathrm{CHCl}_{3}$. If this arose from use of $\mathrm{CDCl}_{3}$ as NMR solvent, we considered that this would be potentially reactive to $\mathrm{KO} t \mathrm{Bu}{ }^{19}$ Indeed, when we mixed phenanthroline and $\mathrm{KO} t \mathrm{Bu}$ in $\mathrm{THF}$ at room temperature for $2 \mathrm{~h}$ and then diluted with $\mathrm{CDCl}_{3}$, the ${ }^{1} \mathrm{H}$ 
NMR showed almost total collapse of the tert-butoxide signal (Figure 4).

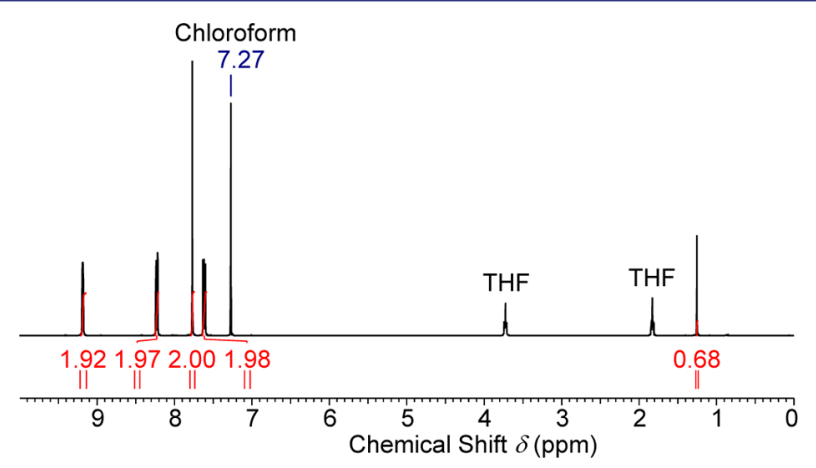

Figure 4. ${ }^{1} \mathrm{H}$ NMR of phenanthroline and $\mathrm{KO} t \mathrm{Bu}$ in THF after the addition of $\mathrm{CDCl}_{3}$ as the NMR solvent, showing collapse of the tertbutoxide peak.

Wilden further noted that analyzing a mixture of potassium pentoxide and phenanthroline by mass spectrometry suggests that butanone is a major component of the reaction mixture. However, since the mixture was handled in THF and since THF has the same molecular formula as butanone, reassurance would be needed about this experiment. Moreover, DiRocco reports $^{20}$ that the fragmentation of tert-pentoxyl radical does not afford butanone together with the methyl radical in significant amounts but rather gives rise to acetone and the (more stable) ethyl radical.

Hence it is seen that these reports do not provide convincing evidence of any direct electron transfer from the butoxide anion of $\mathrm{KO} t \mathrm{Bu}$.

\section{REDUCTIVE FRAGMENTATION OF DITHIANES}

Quite aside from the coupling reactions, potassium tertbutoxide has also been proposed as an electron donor in a number of other reactions, among them the photoinduced cleavage of dithianes reported by Peñéñory et al. (Scheme 5). ${ }^{11}$

\section{Scheme 5. Photo-induced Cleavage Reaction of 2,2-} Diphenyl-1,3-dithiane, 6

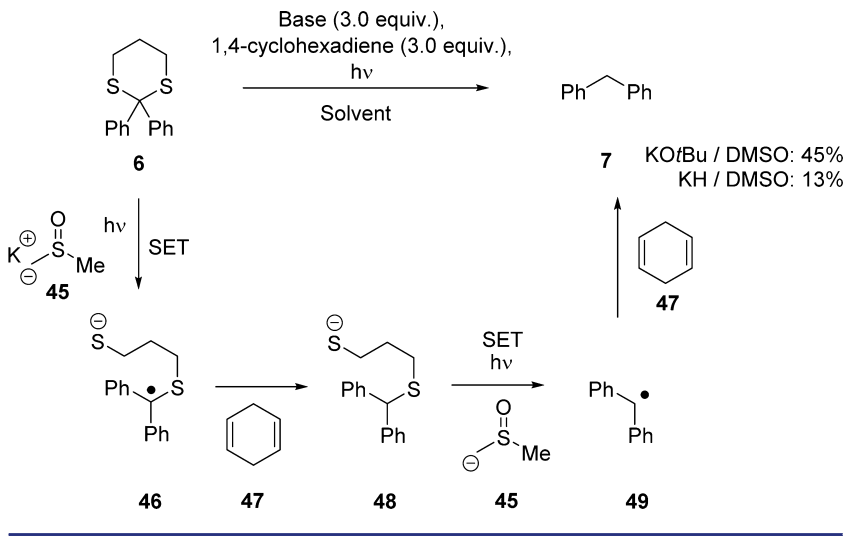

In this reaction, a charge-transfer complex had been reported as characterized by UV-vis spectroscopy between $\mathrm{KO} t \mathrm{Bu}$ and the dithiane, and so this appeared to be the best documented case where electron transfer from tert-butoxide might be observed, albeit with photochemical assistance. Indeed, when a solution of 2,2-diphenyl-1,3-dithiane, 6, in DMSO was treated by us with $\mathrm{KO} t \mathrm{Bu}$ and 1,4-cyclohexadiene and exposed to $\mathrm{UV}$ irradiation, diphenylmethane 7 was the major product $(45 \%$ isolated yield), in agreement with the literature findings.

The reported stable charge transfer complex between dithiane $\mathbf{6}$ and $\mathrm{KO} t \mathrm{Bu}$ had been assigned to a peak at 467 $\mathrm{nm}$ in the UV-visible spectrum. ${ }^{11}$ On mixing dithiane 6 in DMSO with $\mathrm{KO} t \mathrm{Bu}$, we also observed a similar absorption at $466 \mathrm{~nm}$ (Figure 5, red trace). However, in view of our

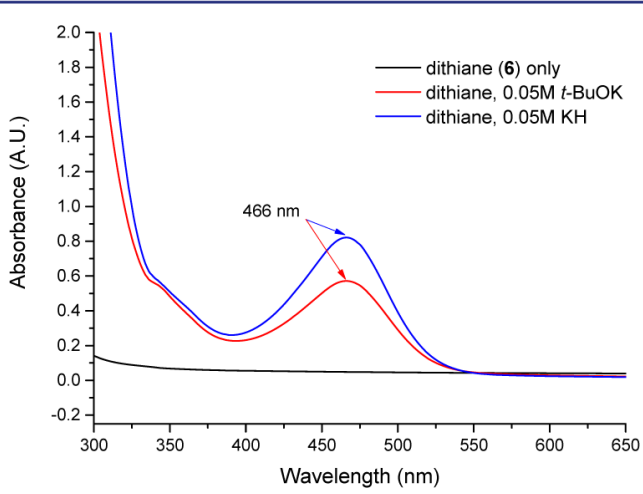

Figure 5. UV-visible spectra of 2,2-diphenyl-1,3-dithiane, 6, in DMSO without base (black trace), of 6 in DMSO with KOtBu (red trace), and of 6 in DMSO with $\mathrm{KH}$ as base (blue trace).

misgivings about the role of $\mathrm{KO} \mathrm{tBu}$ as a single electron donor, we considered whether there might be an alternative role for the $\mathrm{KO} t \mathrm{Bu}$. Repetition of the reaction using $\mathrm{KH}$ as the base rather than $\mathrm{KO} t \mathrm{Bu}$ also led to the isolation of 7 , albeit in a lower yield of $13 \% .{ }^{21}$ Most interestingly, the UV-vis spectrum of the mixture of $6, \mathrm{DMSO}$, and $\mathrm{KH}$ also showed an absorption at $466 \mathrm{~nm}$, while a mixture of $6, \mathrm{DMF}$, and $\mathrm{KO} t \mathrm{Bu}$ gave no such absorption (See SI for UV-vis traces). These results suggest that rather than a charge transfer complex between dithiane 6 and $\mathrm{KO} t \mathrm{Bu}$, a charge transfer complex between dithiane $\mathbf{6}$ and the dimsyl salt $\mathbf{4 5}$ is the likely source of the UV absorptions measured. Therefore, even under photoactivated conditions, evidence supporting direct electron transfer from $\mathrm{KO}$ Bu is lacking.

\section{4. $\mathrm{S}_{\mathrm{RN}} 1$ REACTIONS IN DMF}

Recently, a number of authors have proposed electron transfer reactions when $\mathrm{KO} t \mathrm{Bu}$ was reacted in DMF with various types of substrate. In particular, the team of Yan suggested that a complex of $\mathrm{KO} t \mathrm{Bu}$ with DMF could act as an electron donor to another molecule of DMF. ${ }^{22}$ The most recent was an intriguing study by Taillefer et al. which investigated $S_{\mathrm{RN}} 1$ reactions of aryl radicals $\mathbf{3}$ with potassium enolates $\mathbf{1 0}$ in the absence of photoexcitation (Scheme 1C). ${ }^{12}$ They found that DMF was unique among solvents in promoting these reactions. It is known that $\mathrm{KO} t \mathrm{Bu}$ can deprotonate $\mathrm{DMF}{ }^{23}$ but their proposal was that the anion of the resulting salt 8 behaves as an electron donor to aryl halides, affording the corresponding carbamoyl radical 9 and an aryl radical 3. Radical 3 then combines with enolate 10 to give radical anion 11. Electron transfer to another molecule of 1 continues the chain process and affords product 12. Their computational studies show that their proposal follows an energetically viable pathway, in which potassium ions play a special role, although there is no experimental support for their proposal from anion $\mathbf{8}^{24}$

Our experience with probing electron transfer reactions using substrate $\mathbf{3 5}$ attracted us to test for an electron transfer pathway using $\mathrm{DMF}$ and $\mathrm{KO} t \mathrm{Bu}$ ( 2 equiv) in benzene under previously 
tested conditions. This substrate cannot undergo side-reactions via formation of benzyne but is converted to the corresponding aryl radical following electron transfer. This aryl radical is hindered and undergoes competing signature reactions, namely, (i) addition to benzene, leading to substituted biphenyl $\mathbf{5 0}$ (see drawing above Table 1) and (ii) hydrogen abstraction from

Table 1. Comparison of Reactivity of DMF and Diformamides in Coupling Reactions That Use KOtBu as Base

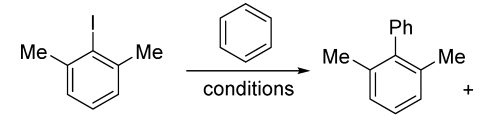

35

\begin{tabular}{llc} 
& \multicolumn{1}{c}{ additive } & $\mathbf{5 0 + \mathbf { 5 1 } ^ { d }}(\%)$ \\
$1^{a}$ & none & 0.5 \\
$2^{a}$ & DMF $\left(1 \%^{c}\right)$ & 2.6 \\
$3^{a}$ & DMF $(0.1 \mathrm{mmol})$ & 0.6 \\
$4^{a}$ & $\mathbf{5 5}(0.05 \mathrm{mmol})$ & 8.0 \\
$5^{a}$ & $\mathbf{5 8}(0.05 \mathrm{mmol})$ & 16.1 \\
$6^{b}$ & DMF $\left(1 \%^{c}\right)$ & 0.4 \\
$7^{b}$ & $\mathbf{5 5}\left(0.5 \%^{c}\right)$ & 19.6 \\
$8^{b}$ & $\mathbf{5 8}\left(0.5 \%^{c}\right)$ & 31.6
\end{tabular}

${ }^{a}$ Substrate $35(0.5 \mathrm{mmol}), 1 \mathrm{mmol} \mathrm{KOtBu}$, benzene as solvent, 130 ${ }^{\circ} \mathrm{C}, 18 \mathrm{~h} .{ }^{b}$ Reaction at $110{ }^{\circ} \mathrm{C}, 4 \mathrm{~h} .{ }^{c}$ Relative to benzene (v/v) as solvent. ${ }^{d}$ As determined by internal standard $\left({ }^{1} \mathrm{H}\right.$ NMR, see SI).

benzene affording a phenyl radical that leads to the volatile $m$ xylene, as well as biphenyl $\mathbf{5 1}$, where the ratio of $\mathbf{5 0 / 5 1}$ is ca. $1: 3.5 .^{5 f, 8}$ This substrate has given very valuable mechanistic information in studies to date.

With this substrate, when the reaction was conducted in the absence of DMF, only a barely detectable amount of biphenyls was seen (entry 1). In contrast, using DMF ( $1 \% \mathrm{v} / \mathrm{v}$ wrt the solvent benzene) and $\mathrm{KO} t \mathrm{Bu}$ ( 2 equiv) for $18 \mathrm{~h}$ at $130{ }^{\circ} \mathrm{C}$, coupling was observed to afford a mixture of biphenyls $\mathbf{5 0}$ and 51, in their characteristic ratio, in a small, but measurable amount (entry 2). This clearly indicated that an electron donor was being produced from the reaction involving $\mathrm{KO} t \mathrm{Bu}$ and DMF.

As mentioned, Scheme $1 \mathrm{C}$ is the current working hypothesis proposed by Taillefer for the reductions observed with $\mathrm{KO} t \mathrm{Bu}$ in DMF. However, in Scheme 6, we suggest an alternative

Scheme 6. Forming Electron Donors from Formamides
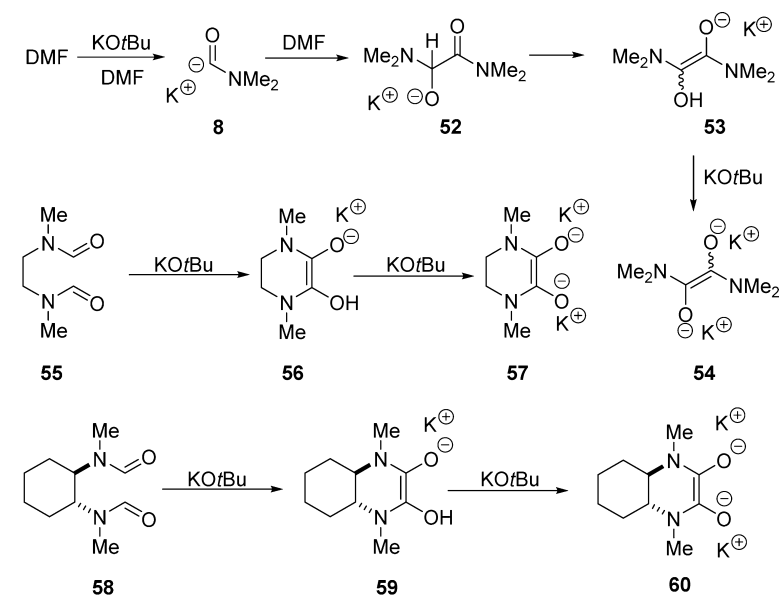

electron donor. The DMF-derived anion $\mathbf{8}$ is known to act as a nucleophile; $^{23}$ if it attacks a neutral DMF molecule, this forms anion 52. Proton transfer affords the enolate 53, which is a candidate electron donor. Alternatively, further deprotonation should afford the dianion 54, an even better electron donor. ${ }^{8}$ These species could then initiate electron transfer to aryl iodides to form aryl radicals, after which an $S_{\mathrm{RN}} 1$ chain reaction would follow. Checking the literature shows that reaction of carbamoyl anions with formamides has already been reported, affording dianions similar to those shown in Scheme $6 .^{25}$

To distinguish between the two proposals for DMF, we made use of the effective concentration of electron donor for initiating the coupling of iodoarenes to benzene. Our plan was to compare the abilities of $\mathbf{5 5}$ with $\mathrm{DMF}$ in triggering the reactions in benzene as solvent. Specifically, we would compare (i) the reaction in the presence of a fixed concentration of $\mathbf{5 5}$ with (ii) the reaction with twice this concentration of DMF. If the acyl anion $\mathbf{8}$ were the electron donor, then a fixed concentration, $x$, of $\mathbf{5 5}$ might work equally as well as twice that concentration, $2 x$, of DMF, since equal concentrations of formyl groups would be present in both reactions. But if the electron transfer agents are $\mathbf{5 3}$ or $\mathbf{5 4}$ (when DMF is used), which requires a dimerization to form an organic electron donor, then the fixed concentration of additive $\mathbf{5 5}$ should work much better than twice that concentration of DMF, since the positioning of the formyl groups $[1,6]$ to each other in $\mathbf{5 5}$ would give a massive advantage for formation of such an electron donor by intramolecular reaction in terms of effective molarity, compared with intermolecular dimerization of two molecules of DMF. Formation of higher concentrations of electron donors would lead to higher conversion of substrate 35 over a defined time period.

When the amount of DMF was lowered $(0.1 \mathrm{mmol}, 0.2$ equiv, Table 1, entry 3 ), a trace amount of biaryls was formed $(0.6 \%)$. However, under the same reaction conditions using linear diformamide 55 ( $0.05 \mathrm{mmol}, 0.1$ equiv., entry 4$)$, a very clear increase in the amount of biaryls formed was seen $(8.0 \%)$. If our proposal about the cyclization of additive $\mathbf{5 5}$ is correct, then introducing the more conformationally restricted diformamide $\mathbf{5 8}$ should be even more successful, and this was indeed the case, providing $16.1 \%$ of biaryl products (entry 5) and reacting through electron donors 59 or 60 . At $110{ }^{\circ} \mathrm{C}$ for 4 $\mathrm{h}$ and using an increased amount of additive (1\% DMF, $0.5 \%$ $\mathbf{5 5}$ or 58) a similar trend of an increased quantity of biaryls was observed when switching from DMF to linear diformamide $\mathbf{5 5}$ (entries 6 and 7). A further increase in biaryl yield was observed when cyclic diformamide $\mathbf{5 8}$ was used (entry 8).

We explored computationally our proposed reactions between substrate 35 and $(Z)-54,(E)-54$, and 60 (see SI file for details). These reactions showed very achievable barriers $\left(\Delta G^{*}\right)$ of $30.2,23.6$, and $28.1 \mathrm{kcal} / \mathrm{mol}$ with the solvent benzene modeled as a continuum. [The M062X functional ${ }^{26,27}$ was used with the $6-311++G(d, p)$ basis set $^{28-32}$ on all atoms, except for the iodine. Iodine was modeled with the MWB46 relativistic pseudopotential and associated basis set. ${ }^{33}$ All calculations were carried out using the C-PCM implicit solvent model $^{34,35}$ as implemented in Gaussian09. ${ }^{36}$ ] The combined experimental and computational results provide strong evidence in support of the ability of formamides to dimerize in the presence of $\mathrm{KO} t \mathrm{Bu}$ to form electron donors and hence provides an alternative to the proposals of Taillefer. 


\section{CAN KOtBu EVER ACT AS A DIRECT ELECTRON DONOR?}

The reluctance of $\mathrm{KO} t \mathrm{Bu}$ to act as electron donor to aryl iodides in section 2 arises from the mismatch of the redox potentials. As mentioned above, aryl iodides have reduction potentials at $-2.0 \mathrm{~V}$ vs. SCE, while the oxidation potential of $\mathrm{KO} t \mathrm{Bu}$ is at $+0.10 \mathrm{~V}$ vs. SCE in DMF. ${ }^{6 \mathrm{e}}$ This does not mean that $\mathrm{KO} t \mathrm{Bu}$ would never act as electron donor. The search for a suitable system to demonstrate this phenomenon revealed a series of studies by Schreiner and Fokin et al. on the reaction between $\mathrm{KOH}$ and $\mathrm{CBr}_{4}, 61$, in the presence of adamantane and a phase transfer agent, where selective bromination at the methine positions of adamantane was observed (Scheme 7). ${ }^{37}$

\section{Scheme 7. Hydroxide ${ }^{37}$ and tert-Alkoxides as Electron} Donors to $\mathrm{CBr}_{4}$

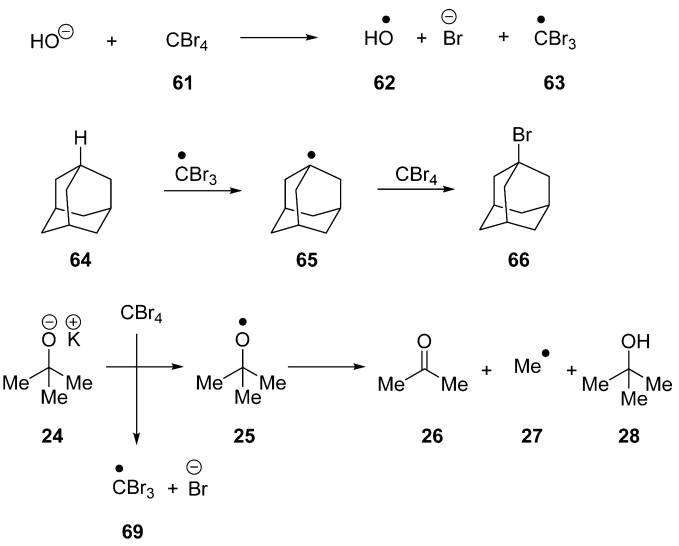

This was explained by electron transfer from hydroxide to $\mathrm{CBr}_{4}$, to afford a bromide anion and a tribromomethyl radical, 63. This radical is highly selective in abstracting the methine hydrogen to form the 1-adamantyl radical, 65, which in turn abstracted a $\mathrm{Br}$ atom from $\mathrm{CBr}_{4}$ to form 1-bromoadamantane 66. Given that the reduction potential of $\mathrm{CBr}_{4}$ is known in DMF $(-0.31 \mathrm{~V} \text { vs. SCE })^{38}$ and that it represents a much more accessible reduction potential for tert-butoxide anion in $\mathrm{KO} t \mathrm{Bu}$, we undertook a study of the reaction of tertiary alkoxide $\mathbf{2 4}$ with $\mathrm{CBr}_{4}$ under similar conditions to Schreiner, except that we did not add a phase transfer salt. Reaction of $\mathrm{KO} t \mathrm{Bu}$ with $\mathrm{CBr}_{4}$ in DCM, following the conditions of Schreiner, selectively afforded 1-bromoadamantane, 66, in line with his selective reaction where he had used potassium hydroxide, $\mathrm{KOH}^{39}$ Our experiments were backed by computation, which showed that electron transfer from $\mathrm{KO} t \mathrm{Bu}$ to $\mathrm{CBr}_{4}$ featured a very achievable barrier of $23.3 \mathrm{kcal} \mathrm{mol}^{-1}$. [The M062X functional $^{26,27}$ was used with the $6-311++G(d, p)$ basis set $^{28-32}$ on all atoms, except for the bromine. Bromine was modeled with the MWB28 relativistic pseudopotential and associated basis set. $^{33}$ All calculations were carried out using the C-PCM implicit solvent model $^{34,35}$ as implemented in Gaussian09. ${ }^{36}$ ] This supports the idea that $\mathrm{KO} t \mathrm{Bu}$ can undergo electron transfer to an electrophile with a suitable reduction potential, such as $\mathrm{CBr}_{4}$.

In summary, reports on the unique capacity of $\mathrm{KO} t \mathrm{Bu}$ to cause unusual reactions have appeared regularly in the recent literature: (i) In the cases of transition metal-free coupling reactions, where the reactions are conducted in an arene solvent, to date there is no evidence to support $\mathrm{KO} t \mathrm{Bu}$ acting directly as an electron donor to an aryl halide. This finding accords both with electrochemical information on the oxidation potential of $\mathrm{KO} t \mathrm{Bu}$ and with computational evidence, as well as with our published lack of reaction between $\mathrm{KO} t \mathrm{Bu}$ and 2-iodo$m$-xylene, 35 . $^{5 \mathrm{~b}, \mathrm{f}}$ (ii) Reaction of $\mathrm{KO}$ tBu with DMSO leads to the dimsyl anion, which acts as an electron donor to appropriate substrates. ${ }^{40}$ (iii) Reaction of $\mathrm{KO} t \mathrm{Bu}$ with $\mathrm{DMF}$ affords electron transfer activity also, but here, our experiments indicate a role for a dimerization of formamides to afford novel and strong organic electron donors. ${ }^{25}$ Thus, in all these cases, it is the behavior of $\mathrm{KO} t \mathrm{Bu}$ as a base that gives access to these electron transfer reactions. The greater basicity of the $\mathrm{KO} t \mathrm{Bu}$ over its sodium and lithium counterparts likely results from the difference in the metal-oxygen bonding in these salts. ${ }^{14}$

Finally, in pursuit of likely examples of direct electron transfer from $\mathrm{KO} t \mathrm{Bu}$, we mirrored earlier experiments of Schreiner, who had used $\mathrm{KOH}$ with $\mathrm{CBr}_{4}$. The substrate $\mathrm{CBr}_{4}$ has a reduction potential near to the oxidation potential of $\mathrm{KO} t \mathrm{Bu}$ and, in the presence of adamantane as a reporter molecule, leads to 1-bromoadamantane via the generation of tribromomethyl radicals. Computational studies show that in this case, electron transfer from $\mathrm{KO} t \mathrm{Bu}$ is the likely source of these radicals. This study does address a number of cases where $\mathrm{KO} t \mathrm{Bu}$ has been associated with electron transfer, but we are now investigating yet further cases ${ }^{41}$ and will report on those in due course.

\section{ASSOCIATED CONTENT}

\section{S Supporting Information}

The Supporting Information is available free of charge on the ACS Publications website at DOI: 10.1021/jacs.6b03282.

Experimental procedures including the synthesis of substrates, important NMR spectra, cyclic voltammetry and EPR studies, and computational coordinates (PDF)

\section{AUTHOR INFORMATION}

\section{Corresponding Authors}

*John.Murphy@strath.ac.uk

*tell.tuttle@strath.ac.uk

\section{Author Contributions}

${ }^{\perp}$ J.P.B. and G.C. contributed equally.

\section{Notes}

The authors declare no competing financial interest.

\section{ACKNOWLEDGMENTS}

We thank Prof. John C. Walton for assistance and advice on EPR. We thank EPSRC (current Grant Number EP/K033077/ 1) and GSK, AstraZeneca, and the University of Strathclyde for funding. High resolution mass spectra were obtained at the EPSRC National Mass Spectrometry Centre, Swansea.

\section{REFERENCES}

(1) (a) Yanagisawa, S.; Ueda, K.; Taniguchi, T.; Itami, K. Org. Lett. 2008, 10, 4673-4676. (b) Sun, C.-L.; Li, H.; Yu, D.-G.; Yu, M.; Zhou, X.; Lu, X.-Y.; Huang, K.; Zheng, S.-F.; Li, B.-J.; Shi, Z.-J. Nat. Chem. 2010, 2, 1044-1049. (c) Shirakawa, E.; Itoh, K.-I.; Higashino, T.; Hayashi, T. J. Am. Chem. Soc. 2010, 132, 15537-15539. Note: this paper also demonstrated effective reactions with $\mathrm{NaO} t \mathrm{Bu}$. (d) Liu, W.; Cao, H.; Zhang, H.; Zhang, H.; Chung, K. H.; He, C.; Wang, H.; Kwong, F. Y.; Lei, A. J. Am. Chem. Soc. 2010, 132, 16737-16740.

(2) (a) Sun, C. L.; Gu, Y.-F.; Wang, B.; Shi, Z.-J. Chem. - Eur. J. 2011, 17, 10844-10847. (b) Sun, C. L.; Gu, Y.-F.; Huang, W.-P.; Shi, Z.-J. 
Chem. Commun. 2011, 47, 9813-9815. (c) Shirakawa, E.; Zhang, X.; Hayashi, T. Angew. Chem., Int. Ed. 2011, 50, 4671-4674. (d) Yong, G.P.; She, W.-L.; Zhang, Y.-M.; Li, Y.-Z. Chem. Commun. 2011, 47, 11766-11768. (e) Rueping, M.; Leiendecker, M.; Das, A.; Poisson, T.; Bui, L. Chem. Commun. 2011, 47, 10629-10631. (f) Qiu, Y.; Liu, Y.; Yang, K.; Hong, W.; Li, Z.; Wang, Z.; Yao, Z.; Jiang, S. Org. Lett. 2011, 13, 3556-3559. (g) Roman, D. S.; Takahashi, Y.; Charette, A. B. Org. Lett. 2011, 13, 3242-3245.

(3) (a) Shirakawa, E.; Hayashi, T. Chem. Lett. 2012, 41, 130-134. (b) Liu, H.; Yin, B.; Gao, G. Z.; Li, Y.; Jiang, H. Chem. Commun. 2012, 48, 2033-2035. (c) Chen, W.-C.; Hsu, Y.-C.; Shih, W.-C.; Lee, C.-Y.; Chuang, W.-H.; Tsai; Chen, P. P.-Y.; Ong, T.-G. Chem. Commun. 2012, 48, 6702-6704. (d) Pieber, B.; Cantillo, D.; Kappe, O. C. Chem. - Eur. J. 2012, 18, 5047-5055. (e) Bhakuni, B. S.; Kumar, A.; Balkrishna, S. J.; Sheikh, J. A.; Konar, S.; Kumar, S. Org. Lett. 2012, 14, 2838-2841. (f) Ng, Y. S.; Chan, C. S.; Chan, K. S. Tetrahedron Lett. 2012, 53, 3911-3914. (g) De, S.; Ghosh, S.; Bhunia, S.; Sheikh, J. A.; Bisai, A. Org. Lett. 2012, 14, 4466-4469. (h) Tanimoro, K.; Ueno, M.; Kirihata, M.; Tanimori, S. J. Org. Chem. 2012, 77, 7844-7849. (i) Wu, Y.; Wong, S. M.; Mao, F.; Chan, T. L.; Kwong, F. Y. Org. Lett. 2012, $14,5306-5309$.

(4) (a) Zhao, H.; Shen, J.; Guo, J.; Ye, R.; Zeng, H. Chem. Commun. 2013, 49, 2323-2325. (b) Buden, M. E.; Guastavino, J. F.; Rossi, R. A. Org. Lett. 2013, 15, 1174-1177. (c) Liu, W.; Tian, F.; Wang, X.; Yu, H.; Bi, Y. Chem. Commun. 2013, 49, 2983-2985. (d) Kumar, A.; Bhakuni, B. S.; Prasad, Ch. D.; Kumar, S.; Kumar, S. Tetrahedron 2013, 69, 5383-5392. (e) De, S.; Mishra, S.; Kakde, B. N.; Dey, D.; Bisai, A. J. Org. Chem. 2013, 78, 7823-7844. (f) Sharma, S.; Kumar, M.; Kumar, V.; Kumar, N. Tetrahedron Lett. 2013, 54, 4868-4871. (g) Dewanji, A.; Murarka, S.; Curran, D. P.; Studer, A. Org. Lett. 2013, $15,6102-6105$.

(5) (a) Wu, Y.; Choy, P. Y.; Kwong, F. Y. Org. Biomol. Chem. 2014, 12, 6820-6823. (b) Zhou, S.; Anderson, G. M.; Mondal, B.; Doni, E.; Ironmonger, V.; Kranz, M.; Tuttle, T.; Murphy, J. A. Chem. Sci. 2014, 5, 476-482. (c) Guastavino, J. F.; Buden, M. E.; Rossi, R. A. J. Org. Chem. 2014, 79, 9104-9111. (d) Bhakuni, B. S.; Yadav, A.; Kumar, S.; Patel, S.; Sharma, S.; Kumar, S. J. Org. Chem. 2014, 79, 2944-2954. (e) Cuthbertson, J.; Gray, V. J.; Wilden, J. D. Chem. Commun. 2014, 50, 2575-2578. (f) Zhou, S.; Doni, E.; Anderson, G. M.; Kane, R. G.; MacDougall, S. W.; Ironmonger, V. M.; Tuttle, T.; Murphy, J. A. J. Am. Chem. Soc. 2014, 136, 17818-17826. (g) Ghosh, D.; Lee, J.-Y.; Liu, C.Y.; Chiang, Y.-H.; Lee, H. M. Adv. Synth. Catal. 2014, 356, 406-410. (h) Zheng, X.; Yang, L.; Du, W.; Ding, A.; Guo, H. Chem. - Asian J. 2014, 9, 439-442. Bhakuni, B. S.; Yadav, A.; Kumar, S.; Kumar, S. New J. Chem. 2014, 38, 827-836.

(6) (a) Liu, W.; Xu, L. G. Tetrahedron 2015, 71, 4974-4981. (b) Liu, W.; Liu, R.; Bi, Y. Tetrahedron 2015, 71, 2622-2628. (c) Doni, E.; Zhou, S.; Murphy, J. A. Molecules 2015, 20, 1755-1774. (d) Masters, K.-S. RSC Adv. 2015, 5, 29975-29986. (e) Yi, H.; Jutand, A.; Lei, A. Chem. Commun. 2015, 51, 545-548.

(7) Patil, M. J. Org. Chem. 2016, 81, 632-639.

(8) Barham, J. P.; Coulthard, G.; Kane, R. G.; Delgado, N.; John, M. P.; Murphy, J. A. Angew. Chem., Int. Ed. 2016, 55, 4492-4496.

(9) Sun, C. L.; Gu, Y.-F.; Wang, B.; Shi, Z.-J. Chem. - Eur. J. 2011, 17, 10844-10847.

(10) Studer, A.; Curran, D. P. Angew. Chem., Int. Ed. 2011, 50, 50185022.

(11) Oksdath-Mansilla, G.; Argüello, J. E.; Peñeñory, A. B. Tetrahedron Lett. 2013, 54, 1515-1518.

(12) Pichette Drapeau, M.; Fabre, I.; Grimaud, L.; Ciofini, I.; Ollevier, T.; Taillefer, M. Angew. Chem., Int. Ed. 2015, 54, 1058710591.

(13) (a) Murphy, J. A.; Khan, T. A.; Zhou, S.-Z.; Thomson, D. W.; Mahesh, M. Angew. Chem., Int. Ed. 2005, 44, 1356-1360. (b) Murphy, J. A.; Zhou, S.-Z.; Thomson, D. W.; Schoenebeck, F.; Mahesh, M.; Park, S. R.; Tuttle, T.; Berlouis, L. E. A. Angew. Chem., Int. Ed. 2007, 46, 5178-5183. (c) Murphy, J. A.; Garnier, J.; Park, S. R.; Schoenebeck, F.; Zhou, S.-Z.; Turner, A. T. Org. Lett. 2008, 10, 1227-1230. (d) Farwaha, H. S.; Bucher, G.; Murphy, J. A. Org. Biomol.
Chem. 2013, 11, 8073-8081. (e) Hanson, S. S.; Doni, E.; Traboulsee, K. T.; Coulthard, G.; Murphy, J. A.; Dyker, C. A. Angew. Chem., Int. Ed. 2015, 54, 11236-11239.

(14) One facet that Patil's paper ${ }^{7}$ addresses is a possible special role for potassium ions in assisting the activation of aryl iodides. This may explain why $\mathrm{KO} t \mathrm{Bu}$, is usually more successful than $\mathrm{NaO} t \mathrm{Bu}$ in these activation reactions. See also ref 12 .

(15) Following ref $6 \mathrm{~b}$, our electrochemistry experiments were conducted with tetralkylammonium counterions, not potassium cations; potassium complex $\mathbf{1 3}$ is likely to be a little more easily reducible than 21.

(16) Our SI file shows addition of the elements of $t \mathrm{BuOH}$ to benzyne intermediates. For discussions of such reactions, see: Dong, Y.; Lipschutz, M. I.; Tilley, T. D. Org. Lett. 2016, 18, 1530-1533. Roberts, J. D.; Vaughan, W. C.; Carlsmith, L. A.; Semenow, D. A. J. Am. Chem. Soc. 1956, 78, 611-614. One reviewer has raised the question whether the immediate $\mathrm{KO} t \mathrm{Bu}$ adduct of the benzyne, that is, an $o$ butoxyarylpotassium, might act as an electron donor. This is an interesting question because aryl Grignard reagents can sometimes act as electron donors to aryl halides. See Uchiyama, N.; Shirakawa, E.; Hayashi, T. Chem. Commun. 2013, 49, 364-366.

(17) (a) Williams, A. L.; Oberright, E. A.; Brooks, J. W. J. Am. Chem. Soc. 1956, 78, 1190-1193. (b) Thelen, M.-A.; Felder, P.; Frey, J. G.; Huber, J. R. J. Phys. Chem. 1993, 97, 6220-6225.

(18) (a) King, T. J.; Newall, C. E. J. Chem. Soc. 1962, 367-369. (b) Foster, R.; Mackie, R. K. Tetrahedron 1962, 18, 1131-1135. (c) Pollitt, R. J.; Saunders, B. C. J. Chem. Soc. 1965, 4615-4628. (d) Fyfe, C. A.; Foster, R. Chem. Commun. 1967, 1219.

(19) von E. Doering, W.; Hoffmann, A. K. J. Am. Chem. Soc. 1954, 76, 6162-6165

(20) Di Rocco, D. A.; Dykstra, K.; Krska, S.; Vachal, P.; Conway, D. V.; Tudge, M. Angew. Chem., Int. Ed. 2014, 53, 4802-4806.

(21) Full conversion of dithiane 6 was observed, and a complex mixture was produced, from which the product was isolated.

(22) (a) Wei, W.-T.; Dong, X.-J.; Nie, S.-Z.; Chen, Y.-Y.; Zhang, X.J.; Yan, M. Org. Lett. 2013, 15, 6018-6021. (b) Chen, Y.-Y.; Zhang, X.J.; Yuan, H.-M.; Wei, W.-T.; Yan, M. Chem. Commun. 2013, 49, 10974-10976. (c) Wang, W.-J.; Zhao, X.; Tong, L.; Chen, J.-H.; Zhang, X.-J.; Yan, M. J. Org. Chem. 2014, 79, 8557-8565. (d) Wei, W.T.; Dong, X.-J.; Nie, S.-Z.; Chen, Y.-Y.; Zhang, X.-J.; Yan, M. Org. Lett. 2013, 15, 6018-6021.

(23) (a) Reeves, J. T.; Lorenc, C.; Camara, K.; Li, Z.; Lee, H.; Busacca, C. A.; Senanayake, C. H. J. Org. Chem. 2014, 79, 5895-5902 and references therein. (b) Reeves, J. T.; Tan, Z.; Herbage, M. A.; Han, Z. S.; Marsini, M. A.; Li, Z.; Li, G.; Xu, Y.; Fandrick, K. R.; Gonnella, N. C.; Campbell, S.; Ma, S.; Grinberg, N.; Lee, H.; Lu, B. Z.; Senanayake, C. H. J. Am. Chem. Soc. 2013, 135, 5565-5568.

(24) For a case where experimental observations differ from computational predictions, see: (a) Plata, R. E.; Singleton, D. A. J. Am. Chem. Soc. 2015, 137, 3811-3826. For successful interplay of theory and experiment, see: (b) Sperger, T.; Sanhueza, I. A.; Schoenebeck, F. Acc. Chem. Res. 2016, DOI: 10.1021/acs.accounts.6b00068. (c) Tsang, A. S.-K.; Sanhueza, I. A.; Schoenebeck, F. Chem. - Eur. J. 2014, 20, 16432-16441.

(25) Nudelman, N. S.; Garcia Linares, G. E. J. Org. Chem. 2000, 65, $1629-1635$.

(26) Zhao, Y.; Truhlar, D. G. Acc. Chem. Res. 2008, 41, 157-167.

(27) Zhao, Y.; Truhlar, D. G. J. Chem. Phys. 2006, 125, 194101.

(28) Krishnan, R.; Binkley, J. S.; Seeger, R.; Pople, J. A. J. Chem. Phys. 1980, 72, 650-654.

(29) Frisch, M. J.; Pople, J. A.; Binkley, J. S. J. Chem. Phys. 1984, 80, 3265-3269.

(30) McLean, A. D.; Chandler, G. S. J. Chem. Phys. 1980, 72, 56395648.

(31) Blaudeau, J.-P.; McGrath, M. P.; Curtiss, L. A.; Radom, L. J. Chem. Phys. 1997, 107, 5016-5021.

(32) Clark, T.; Chandrasekhar, J.; Spitznagel, G. W.; Schleyer, P. V. R. J. Comput. Chem. 1983, 4, 294-301. 
(33) Bergner, A.; Dolg, M.; Küchle, W.; Stoll, H.; Preuß, H. Mol. Phys. 1993, 80, 1431-1441.

(34) Cossi, M.; Rega, N.; Scalmani, G.; Barone, V. J. Comput. Chem. 2003, 24, 669-681.

(35) Barone, V.; Cossi, M. J. Phys. Chem. A 1998, 102, 1995-2001.

(36) Frisch, M. J.; Trucks, G. W.; Schlegel, H. B.; Scuseria, G. E.; Robb, M. A.; Cheeseman, J. R.; Scalmani, G.; Barone, V.; Mennucci, B.; Petersson, G. A.; Nakatsuji, H.; Caricato, M.; Li, X.; Hratchian, H. P.; Izmaylov, A. F.; Bloino, J.; Zheng, G.; Sonnenberg, J. L.; Hada, M.; Ehara, M.; Toyota, K.; Fukuda, R.; Hasegawa, J.; Ishida, M.; Nakajima, T.; Honda, Y.; Kitao, O.; Nakai, H.; Vreven, T.; Montgomery, J. A., Jr.; Peralta, J. E.; Ogliaro, F.; Bearpark, M.; Heyd, J. J.; Brothers, E.; Kudin, K. N.; Staroverov, V. N.; Kobayashi, R.; Normand, J.; Raghavachari, K.; Rendell, A.; Burant, J. C.; Iyengar, S. S.; Tomasi, J.; Cossi, M.; Rega, N.; Millam, J. M.; Klene, M.; Knox, J. E.; Cross, J. B.; Bakken, V.; Adamo, C.; Jaramillo, J.; Gomperts, R.; Stratmann, R. E.; Yazyev, O.; Austin, A. J.; Cammi, R.; Pomelli, C.; Ochterski, J. W.; Martin, R. L.; Morokuma, K.; Zakrzewski, V. G.; Voth, G. A.; Salvador, P.; Dannenberg, J. J.; Dapprich, S.; Daniels, A. D.; Farkas, O.; Foresman, J. B.; Ortiz, J. V.; Cioslowski, J.; Fox, D. J. Gaussian 09, (Revision A.02); Gaussian, Inc.: Wallingford, CT, 2009.

(37) Schreiner, P. R.; Lauenstein, O.; Kolomitsyn, I. V.; Nadi, S.; Fokin, A. Angew. Chem., Int. Ed. 1998, 37, 1895-1897. (b) Fokin, A. A.; Schreiner, P. R. Adv. Synth. Catal. 2003, 345, 1035-1052.

(38) Murayama, E.; Kohda, A.; Sato, T. J. Chem. Soc., Perkin Trans. 1 1980, 947-949.

(39) The chemistry in this reaction mixture is not confined to electron transfer from $\mathrm{KO} t \mathrm{Bu}$, and we believe that a competing reaction involves the formation of hypobromites, although they are not involved in the bromination of adamantane. This forms part of a comprehensive study that we hope to publish shortly.

(40) Previous papers that discussed the possibility of dimsyl anion as a single electron donor: (a) Rajan, S.; Muralimohan, K. Tetrahedron Lett. 1978, 19, 483-486. (b) Alonso, R. A.; Rossi, R. A. Tetrahedron Lett. 1985, 26, 5763-5766. (c) Shishlov, N. M.; Khursan, S. L. Russ. J. Phys. Chem. B 2011, 5, 737-747. (d) Øpstad, C. L.; Melø, T. B.; Sliwka, H. R.; Partali, V. Tetrahedron 2009, 65, 7616-7619. (e) Zhang, M.-X.; Hu, X.-H.; Xu, Y.-H.; Loh, T.-P. Asian J. Org. Chem. 2015, 4, 1047-1049.

(41) Ashby, E. C.; Goel, A. B.; DePriest, R. N. J. Org. Chem. 1981, 46, 2429. (b) Ashby, E. C.; Argyropoulos, J. N. J. Org. Chem. 1986, 51, 3593-3597. 